\title{
A capability based framework for customer experience focused digital transformation
}

\author{
Neeraj Sahu \\ School of Business Information Technology and Logistics \\ RMIT University \\ Melbourne, Australia \\ Email: neeraj.sahu@student.rmit.edu.au
}

\section{Hepu Deng}

School of Business Information Technology and Logistics

RMIT University

Melbourne, Australia

Email: hepu.deng@rmit.edu.au

\author{
Alemayehu Molla \\ School of Business Information Technology and Logistics \\ RMIT University \\ Melbourne, Australia \\ Email: alemayehu.molla@rmit.edu.au
}

\section{Abstract}

Digital transformation has a potential to deliver numerous values for an organisation through transforming its business models, organisational processes, products and services, and customer engagement. Such a transformation assists organisations to create new capabilities to better serve customers, leading to the improvement of customer experience. As a result, numerous organisations have been investing in digital transformation in today's dynamic environment. There is however, lack of a comprehensive framework for facilitating the implementation of digital transformation in organisations towards improving customer experience. This paper develops a capability based framework for digital transformation in organisations with respect to improving customer experience. Such a framework consisting of analytics, business, customer, and digital is developed through a thematic analysis of qualitative data collected from digital transformation experts in an organisation in Australia using semi-structured interviews. The paper contributes to digital transformation research by the development of a capability framework for better understanding digital transformation in organisations related to the improvement of customer experience.

\section{Keywords}

Digital transformation, customer experience, dynamic capability theory, conceptual framework

\section{Introduction}

Digital transformation is about the change in an organisation `s structure, processes, functions, and business models due to the adoption of digital technologies for radically improving its performance (Matt et al. 2015; Sahu et al. 2018). It integrates digital technologies and organisational processes for generating significant improvements in organisational performance (Westerman et al. 2014a). Digital transformation can provide numerous benefits for an organisation including improving organisational processes, enhancing customer value propositions, improving the quality of customer services, empowering customers, reducing the costs of products and services, innovating new products and services, gaining competitive advantages, increasing customer retention, increasing revenue, and improving customer experience (Davenport 2013; Fitzgerald et al. 2014; Rajabi and Bolhari 2015; Westerman and Bonnet 2015). These benefits motivate organisations to invest in digital transformation.

Digital transformation is growing rapidly in organisations across the world (Kane et al. 2015). Many organisations that involve direct customer interactions are investing significantly in digital transformation (Bharadwaj et al. 2013; Kane et al. 2015; Ward and Peppard 2016). One of the most critical reasons for such a rapid adoption of digital transformation is due to its ability to improve the customer experience in organisations (Westerman et al. 2014b; Duan et al. 2012). Digital transformation equips organisations with various capabilities which assist organisations to enhance their customer processes, engage effectively with their customers, improve features of their products 
and services, and provide better economical and emotional value offerings for their customers, leading to the improvement of customer experience (Piccinini et al. 2015; Sahu et al. 2018).

The implementation of digital transformation for improving customer experience in organisations is a complex process (Matt et al. 2015). It involves managing volatile customer behaviours, understanding complex customer information (Westerman and Bonnet 2015), optimising customer processes (Berman 2012), enhancing business models (Nwankpa and Roumani 2016), integrating various digital technologies (Bharadwaj et al. 2013), and adapting to changing business conditions (Matt et al. 2015). As a result, the development of a specific framework of digital transformation towards improving the customer experience would improve the implementation of digital transformation in organisations.

Many studies have examined the implementation of digital transformation towards improving customer experience in organisations (Kane et al. 2015). Hess et al. (2015), for example, evaluate the strategies and the procedures for implementing digital transformation towards improving customer experience in organisations. Klaus and Nguyen (2013) examine the customer engagement processes to implement digital transformation for improving customer experience. Berman (2012) analyses the critical factors for reshaping the customer value proposition for enhancing customer experience in digital transformation. These studies tend to focus primarily on the implementation of digital transformation for improving customer experience from the technical and process perspectives. Few attempts have been made to develop a comprehensive framework for facilitating the implementation of digital transformation for improving customer experience in organisations.

This paper develops a comprehensive framework of digital transformation for improving customer experience in organisations. The framework consisting of four dimension including analytics, business, customer, and digital is tested and validated through analysing the data collected from semi-structured interviews with digital transformation experts. The findings of this study can assist organisations to better implement digital transformation initiatives for improving customer experience in organisations.

The rest of the paper is organised as follows. Section 2 presents a review of the related literature on digital transformation for improving customer experience, therefore justifying the need for this study. Section 3 presents a conceptual framework for digital transformation. Section 4 describes the research methodology that this study has adopted. Subsequently, Section 5 presents a revised capability framework for facilitating digital transformation towards improving customer experience in organisations. Finally, Section 7 presents the conclusion for this research.

\section{Related literature}

The implementation of digital transformation in organisations is a complex process (Matt et al. 2015). It involves several phases including (a) strategy formulation in which long term strategies and policies for digital transformation are prepared (Hess et al. 2016; Kane et al. 2015), (b) organisational analysis in which the need for digital transformation is discussed (Berman 2012; Ward and Peppard 2016), (c) transformation implementation in which digital transformation strategies and policies are executed (Fitzgerald et al. 2014; Matt et al. 2015), (d) change management in which specific changes related to people, processes, and technologies, due to the adoption of digital transformation are managed (Beetham and Sharpe 2013; Berman 2012; Henfridsson et al. 2014), and (e) performance evaluation in which the outcomes from implementing digital transformation are evaluated (Ashurst and Hodges 2010; Kane et al. 2015).

The adoption of digital transformation in an organisation can impact various areas including (a) business models, (b) operational processes, (c) products and services, and (d) customer engagement (Berman 2012; Fitzgerald et al. 2014; Ward and Peppard 2016; Westerman et al. 2014a; Westerman et al. 2014b). Digital transformation changes the business model of an organisation by re-designing the cost and revenue structure in an organisation (Hellbe and Leung 2015; Westerman and Bonnet 2015). It often leads to the change of the operational processes in organisations by inducing agilities, improving reliabilities, and enabling transparencies (Becker et al. 2013; Westerman et al. 2014a). Digital transformation affects the offerings of products and services by embedding innovation and improving their features (Fitzgerald et al. 2014; Matt et al. 2015). It changes the customer engagement by improving customer interactions (Berman 2012; Westerman and Bonnet 2015; Westerman et al. 2014a). This shows that the effective implementation of digital transformation in organisations is critical for the prosperity even the survivability of individual organisations (Sahu et al. 2018).

Numerous studies have been conducted to investigate the implementation of digital transformation for improving customer experience in organisations (Kane et al. 2015). These studies primarily focus on four aspects including (a) the formulation of specific strategies for facilitating implementing digital transformation towards improving customer experience (Kane et al. 2015), (b) the development of 
various processes of digital transformation for improving customer experience (Klaus and Nguyen 2013), (c) the integration of digital technologies for improving customer experience (Berman 2012), and (d) the evaluation of the performance of digital transformation for improving customer experience (Berman 2012).

Strategy-oriented research on digital transformation towards improving customer experience focuses on evaluating market situations, understanding customer needs, identifying drives, defining the scope, and developing and implementing strategies (Matt et al. 2015). Palmer et al. (2015), for example, conduct a comprehensive analysis for evaluating specific strategies based on the identification of the critical drivers for digital transformation towards improving customer experience in organisations. Hess et al. (2015) develop the procedure for implementing the digital transformation strategy in organisations for improving customer experience. Tafti et al. (2013) investigate the strategy for digital transformation towards improving customer experience in organisations. These studies help individual organisations better develop specific strategies and policies for digital transformation towards improving customer experience.

Process-based research on digital transformation focuses on exploiting digital transformation capabilities for improving customer processes, increasing customer interactions, and expanding customer engagement (Greenberg 2010). Klaus and Nguyen (2013), for example, explore the processes of digital transformation for enabling multi-channel customer interaction towards improving customer experience in retail banking. Thirumalai and Sinha (2011) investigate the process of digital transformation for improving customer experience in online retailing. These studies help organisations re-design their processes of digital transformation for improving customer experience.

Technology-integrated research on digital transformation concentrates on an integrated use of digital technologies for developing specific organisational capabilities to improve customer experience. Andzulis et al. (2014), for example, examine the impact of integrating social media technologies in organisations for improving customer experience. Huang et al. (2011) investigate the impact of integrating web technologies in financial organisations for improving customer experience. These studies assist organisations better understand the capability of digital technologies and the impact of such technologies on organisations, leading to more effective integration of digital transformation.

Evaluation-based research on digital transformation for improving customer experience focuses on analysing the performance of digital transformation that can lead to the re-designing customer value offerings (Berman 2012). Berman (2012), for example, evaluates the critical factors for reshaping the customer value through better customer collaboration and enhanced customer experience. Hughes et al. (2013) examine the value of digital transformation by enabling customer self-servicing for improving customer experience in organisations. These studies lead to the identification of the critical factors that can create values for customers through examining the relationship between customer value and customer experience (Nylén and Holmström 2015; Spiess et al. 2014).

Overall existing studies have shown their importance of digital transformation for improving customer experience in organisations from different perspectives. There is, however, lack of a comprehensive framework for facilitating the implementation of digital transformation in organisations towards improving customer experience. This shows the need for developing such a framework of digital transformation for improving customer experience in organisations.

\section{A digital transformation framework}

A conceptual framework for this research is developed based on the analysis of existing literature on digital transformation for improving customer experience in the context of the dynamic capability theory. The dynamic capability theory reflects the ability of an organisation to integrate, build, and reconfigure internal and external competences to address rapidly changing environments (Teece et al. 1997). Such a theory provides this research with a solid base to develop the framework consisting of several capabilities that an organisation can exploit for improving customer experience. Referring to dynamic capability theory helps this study in building the understanding of the new internal capabilities derived from digital transformation. It assists in investigating the adaptive nature of organisations towards changes caused by new internal capabilities generated by digital transformation. As a result, dynamic capability theory aids in presenting and evaluating the relationships between digital transformation and customer experience improvement. The proposed conceptual framework consists of four dimensions including (a) analytics, (b) business, (c) customers, and (d) digitalization as shown in Figure 1. 


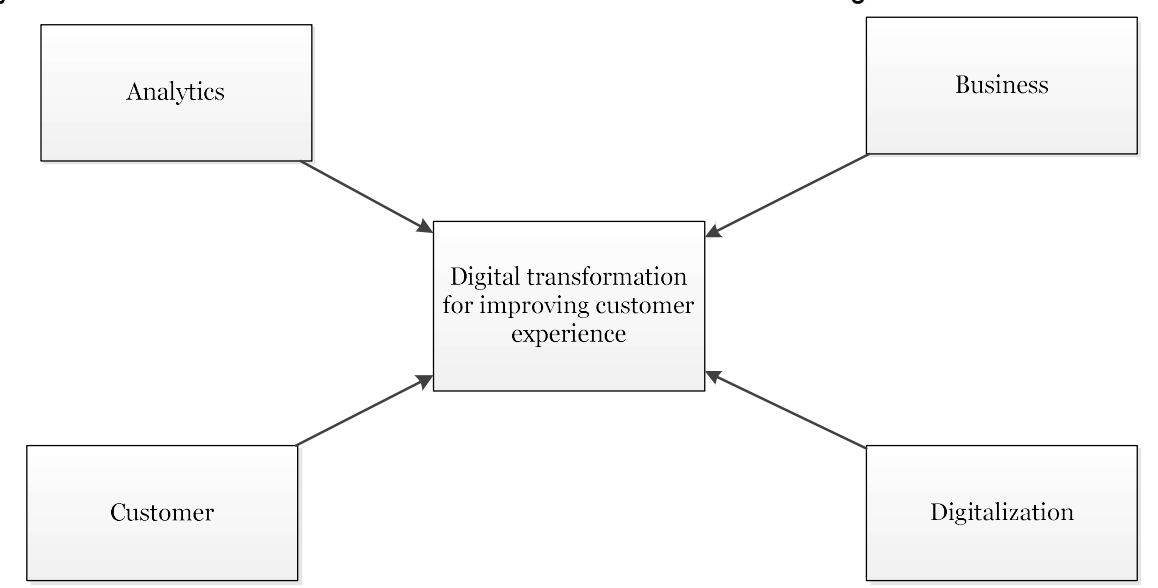

Figure 1: The conceptual framework

\section{Analytics}

The analytics of digital transformation is related to the systematic analysis of customer data using digital technologies for discovering the embedded knowledge in organisations. Such knowledge can help organisations better collaborate with their customers for improving customer experience (Kiron et al. 2012). Analytics facilitate the improvement of the various organisational capabilities related to people, process, functions and technologies in an organisation which eventually triggers the improvement of customer experience. There are various factors that aid the construction of the analytics dimension of the conceptual framework including customer understanding (Fitzgerald et al. 2014; Zhu et al. 2006), digital customer data (Westerman and Bonnet 2015), customer insights (Berman 2012; Kiron et al. 2012), market trends (Andal-Ancion et al. 2012), customer segments (Andal-Ancion et al. 2012; Hess et al. 2016), customer engagement patterns (Ward and Peppard 2016), implementation of customer analytics (Ajmal et al. 2010), data reliability (Astri 2015) and data quality and usability (Olszak and Ziemba 2012). These factors play a very critical role in digital transformation for improving customer experience in organisations.

\section{Business}

The business of digital transformation is about the change of business conditions for improving customer experience through digital transformation. The implementation of digital transformation leads to the change of internal conditions in an organisation including the change in decision making, financial conditions and business performance (Matt et al. 2015). In general, four critical factors including (a) the digital strategy, (b) the business model, (c) the customer value proposition and (d) the business strategy have to be considered in this aspect. There are various business factors that assist in forming the business dimension of the conceptual framework including value creation and delivery (Hess et al. 2016; Matt et al. 2015; Westerman and Bonnet 2015), value proposition (Berman and Marshall 2014; Berman 2012), cost optimisation (Sambamurthy and Zmud 2012), pricing strategy (Bharadwaj et al. 2013), cost reduction (Astri 2015), project management (Mathrani and Viehland 2010) and clear business vision and plan (Olszak and Ziemba 2012). The consideration of these factors in digital transformation is identified as significant towards the improvement of customer experience in organisations.

\section{Customer}

The customer of digital transformation concerns about the entire customer interaction journey with the organisation through digital transformation. It focuses on bi-directional interactions between customers and organisations (Lemon and Verhoef 2016). The indirect interaction happens when customers reach out to an organisation using a generic digital platform such as social media (Straker et al. 2015). In relation to the business of digital transformation, the customer touch points and the customer engagement usually need to be considered. There are various factors that facilitate the development of the customer dimension of the framework including customer collaboration (Berman 2012; Fitzgerald et al. 2014), customer touch points (Berman 2012), customer engagement (Andal-Ancion et al. 2012; Berman 2012), customer feedback, customer servicing (Ward and Peppard 2016), personalised marketing (Kane et al. 2015; Ryan 2016), operational process improvement (Sambamurthy and Zmud 2012), service and product quality (Rajabi and Bolhari 2015; Westerman and Bonnet 2015) customer 
self-serving (Berman 2012; Westerman and Bonnet 2015; Westerman et al. 2011), process transparency (Agarwal et al. 2010), scalability, collaboration, efficiency (Astri 2015), and customer relationship (Mathrani and Viehland 2010). The consideration of these factors is significant towards the success of digital transformation for improving customer experience.

\section{Digitalization}

The digitalization of digital transformation refers to the adaptability, usability and integration-ability of digital technologies with respect to existing infrastructure in organisations (Kino 2011; Tassey 2012). It considers the capabilities of various digital technologies for improving customer experience in organisations. Digital transformation focuses on the adoption of digital technologies in the existing environment. This requires the organisations to carefully consider (a) digital applications, (b) digital platforms, (c) digital infrastructure, (d) functions, and (e) digital channels. There are several factors that enable the construction of the digital dimension of the conceptual framework including digital channels (Fitzgerald et al. 2014), infrastructure capacity (Kane et al. 2015), data security, integration quality (Westerman and Bonnet 2015), infrastructure support (Bharadwaj et al. 2013), and digital content (Kane et al. 2015), technological readiness (Low et al. 2011), scalability (Astri 2015), technology usability (Mathrani and Viehland 2010), technology integration (Ravesteyn and Batenburg 2010) and accessibility (Sahney 2015).

\section{Research methodology}

This study uses a qualitative approach for the development of a digital transformation framework towards improving customer experience. This is because the nature of this study requires the understanding of the beliefs and perceptions of people working in digital transformation in organisations. The use of the qualitative approach enables this study to analyse various perspectives from the experts of digital transformation (Deng and Karunasena 2013). The study employs the Delphi technique based on semi-structured face-to-face interviews for three rounds of iterations for collecting data and sharing the results among the participants to build consensus towards the development of the framework (Hsu and Sandford 2007). The three iterations focus on capturing the critical data to analyse the participant's views and analysing the various perspectives of experts, leading to confirming the capability-based digital transformation framework (Deng and Gupta 2005).

The research is performed in an Australian organisation which has executed digital transformation programs for improving customer experience. The employees from this organisation are recruited to participate in the research. A total of 28 participants are contacted for the study, of which, 21 have accepted to participant in this study. The experience of participants in digital transformation is ranged from 5 years to 18 years. There are various roles that the participants take including executives, product managers, project managers, solution designers, business analysts, and technology developers. The interview questions are developed based on a comprehensive review of the related literature. Participants are first contacted through emails that contain a brief summary about the study. Once the participants accept to volunteer for the study, the details of the interview such as the time and location are communicated to the participant. For each round of iteration, a list of pre-identified questions is prepared for the interview. The average interview lasts for about 60 minutes.

Thematic analysis is adopted for analysing the qualitative data captured. This involves in five stages including transcribing data, organising data, coding data, theming data, and interpreting data (Miles and Huberman 1994). In the first stage, data related to the topic of the study is captured in different formats including notes, diagrams, files, pictures, and supporting reports from the participant. In the second stage, data is transcribed after the interview process. The third stage involves providing codes for performing thematic analysis. The fourth stage consists of three steps including (a) data reduction which focuses on deriving the most relevant data for the research (Alhojailan 2012), (b) data display which focuses on organising, compressing, assembling, and presenting data (Miles and Huberman 1994), and (c) data conclusion which focuses on summing up conclusions (Alhojailan 2012). The fifth stage involves revisiting the research question using the code and themes identified to answer the research question.

\section{Research findings and discussion}

The research findings are organised around four dimensions, namely, analytics, business, customer, and digitalization with the use of thematic analysis. Such dimensions and their sub-dimensions are extracted from the qualitative data collected. A strong linkage between each dimension and its sub-dimensions has been identified. This can ensure that the validated framework can be used for facilitating the implementation of digital transformation for improving customer experience in organisations. 
Analytics

Analytics reflect the characterises of digital transformation in organisations. They relate to performing the computational analysis of customer-related data for identifying useful patterns. Most of the interviewees unanimously assert a positive influence of analytics on digital transformation for improving customer experience. An analysis of the interview data reveals that better analytics result in better customer satisfaction and improved customer experience. The the analytics is explained by three sub-dimensions including (a) data analytics, (b) trends analytics and (b) process analytics.

\section{Data analytics}

Data analytics is about processing customer data captured through various digital channels for better customer understanding. Such customer data is usually related to customers' demographics and attitudinal and purchasing behaviours. Interviewees coherently suggest that better data analytics enable organisations to understand customer trends to execute customer specific strategies for better customer experience. An interviewee states -“...Better data analytics help organisations to target specific customer segments.... This focused approach optimises the effort that an organisation makes to connect with their customers...making customers more valued".

\section{Customer trends analytics}

Customer trends analytics present key insights on the demographical and attitudinal behaviours of customers. They can help organisations to take customer-centric decisions. The study suggests that trend analytics improve customer segmentations, empower organisations with improved insights and showcase customer engagement patterns. An interviewee explains - -"using digital analytics capabilities for improving engagement understanding...we can take many tactical decisions...for our customers...making sure they are happy".

\section{Process analytics}

Process analytics is the systematic analysis of the processes for developing critical understanding of optimising customer processes, leading to the improvement of customer experience in organisations. The process analytics have an ability to provide better customer forecasting analysis, enable predictive marketing and services, integrate real-time information for customers, and trigger real time decisions. One of the interviewees states - "we know what marketing strategies are useful for which customer segments and what services we can use for a particular customer segment... better predictive engagement helps raise financial performance and customer satisfaction".

\section{Business}

The business of digital transformation focuses on aligning the changes to internal and external business conditions with customer offerings for improving customer experience in organisations. An analysis of the interview data highlights the characteristics of the business conditions which make it critical for the organisation to react to the changes through digital transformation so that the customer experience can be improved. The thematic analysis of the business of digital transformation leads to the identification of three sub-dimensions, namely, (a) strategic execution, (b) business model, and (c) value proposition.

\section{Strategic execution}

Strategic execution is related to the implementation of the strategic plan on digital transformation for improving customer experience. It focuses on utilising the digital transformation capabilities for planning the transformation. The study shows that effective strategic execution is reflected through understanding customer needs, providing a single view to customers, enabling customer-centric execution, and adapting to changing market situations. The following interview transcript highlights the importance of adapting to the changing market conditions - "market is changing very rapidly and so is the competition. To retain customers, we need to adopt and change according to the market. We need to adopt new technologies and new ideas for keeping us competitive in market".

\section{Business model}

Business model focuses on streamlining the cost structure, the revenue model, and customer value proposition in digital transformation. It effectively uses the organisation`s internal resources for creating optimal products and services. The study shows that the ability to create better business models helps organisations improve customer satisfaction. The following interview transcript presents the significance of having an effective costing model on customer experience - "making the cost of product 
and services competitive and flexible by optimising various cost factors ..benefits end customer who is consuming it. This helps in achieving better customer experience”.

\section{Value proposition}

A value proposition is about the benefits that customers receive from the offerings of an organisation. The effectiveness of the value proposition is developed through creating unique products and services, innovating new products and services, offering better economic and emotional values to customers, and integrating recognitions and rewards for customers. An interviewee illustrates - "customers are very much aware of the cost and the benefits...using digital transformation we can develop cost effective solutions for our customer ...making them satisfied".

\section{Customer}

The customer of digital transformation considers the entire customer journey where a customer interacts with organisations through various processes and activities for improving their experience. An analysis of the interview data presents a descriptive picture of the attributes of the customer journey and their influence on customer's perception. Interviewees concordantly assert a positive correlation between the attributes of a customer journey and customer experience. This leads to the identification of four sub-themes including (a) processes, (b) collaboration, (c) services and (d) engagement.

\section{Processes}

Processes focus on utilising the digital transformational capabilities to support all customer processes in the customer journey within an organisation. The effectiveness of customer processes is reflected by the automation of the process, the reduction of the operational cost, the simplification of customer processes, the transparency of customer processes, and the coherent customer experience across various channels and devices. The following interview transcript shows the impact of the process transparency on customer experience improvement - "making customer aware of the products, and services and its conditions.....improve customer experience...it avoid misleading customers with non-relevant or technical jargons or incorrect information ...to maintain positive relationship".

\section{Collaboration}

Collaboration focuses on managing customer perceptions and incorporating suggestions from customers about the products and services for improving the value offerings. The customer experience can be captured by focusing on integrating customer feedbacks, providing constant communication to customers, and conducting training for customers. An interviewee state - "improving customer experience requires a lot of customer understanding. This is performed by taking feedback from customers using digital channels about what the customer wants".

\section{Services}

Services are related to the set of tangible values that organisations offer to customers. The study suggests that digital transformation enables organisations with multiple capabilities that help organisations to enhance customer services by enabling better customer experience. Such capabilities are supported through $24 \times 7$ real time servicing, personalise servicing, and self-servicing. A customer experience expert illustrates the importance for inculcating self-services in organisations by digital transformation - "customer self-service triggers three important elements of customer experience, it empowers customers, it gives customers flexibility, and it provides on-demand interaction".

\section{Engagement}

Engagement focuses on utilising the digital transformation capabilities to understand customers and to reach out to them with most appropriate offerings based on their characteristics. The customer engagement is related to personalised marketing, proactive engagement, and integrated offline and online channels. An interviewee reveals the significance of proactive engagement as - "connecting with customer proactively creates a big impact in their experience. ... It includes proactively monitoring their service behaviour, providing push notifications through application, and even reminding them of new offers or deadlines for payments".

\section{Digitalization}

Digitalization is a global theme identified in this study. It reflects the key features, characterises, properties and capabilities of digital technologies for digital transformation. Organisations leverage the digital technology capabilities for better servicing customers. The study reveals that an effective integration of digital technologies allows organisations to generate better features, functions and 
processes for customers, leading to better customer experience. The digitalization theme is abstracted from sub-themes including (a) digital integration, (b) digital capacities and (c) digital capabilities.

\section{Integration}

Digital integration refers to the combination of digital technologies for improving customer experience in organisations. It focuseson better digital enterprise integration, integration with the $3^{\text {rd }}$ party, and social media integration. An interviewee explains the importance of social media integration - "We know our customers use a lot of social media platforms to share a view, or issue and seek information using these forum.....integrating social media provides a very effective way to understand customer ...customer feel empowered when their problem solved using their own preferred medium".

\section{Capabilities}

Capabilities are about the ability of digital technologies in supporting customer processes for improving customer experience in organisations. It is reflected through the ability of digital technologies for providing multiple digital channels, platforms and device independent digital services, high quality digital content, better usability, and data securities and reliabilities. An interviewee highlights the impact of usability - "customer gets annoyed when they deal with complex functions which are difficult to navigate and over information which is irrelevant to them".

\section{Capacities}

Capacities are the ability of digital transformation to provide the maximum level of output in organisations. The study reveals that digital capacities is defined by enhanced system capacities for handling large volumes of customer data, increased processes capacities for processing high speed customer data, improved service speed and performance, and uninterrupted system availability for the customers. An expert suggests the impact of performance and speed on customer experience as - "any lag while accessing the digital content or any other services degrades the customer experience".

The discussion above leads to the development of a digital transformation framework consisting of four dimensions, namely, (a) analytics, (b) business, (c) customer, and (d) digitalization. Each dimension involves various sub-dimensions. The analytics dimension can be effectively influenced by three subdimensions, namely, (a) data analytics, (b) customer trends analytics and (c) process analytics. The business dimension is affected by three sub-dimensions, namely, (a) strategic execution, (b) business model and (c) value proposition. The customer dimension is derived by the effectiveness of four subdimensions, namely, (a) process, (b) collaboration, (c) services and (d) engagement. Finally, the digitalization dimension is reflected through the three sub-dimensions, namely, (a) digital integration, (b) digital capacities and (c) digital capabilities. Figure 2 presents the digital transformation framework.

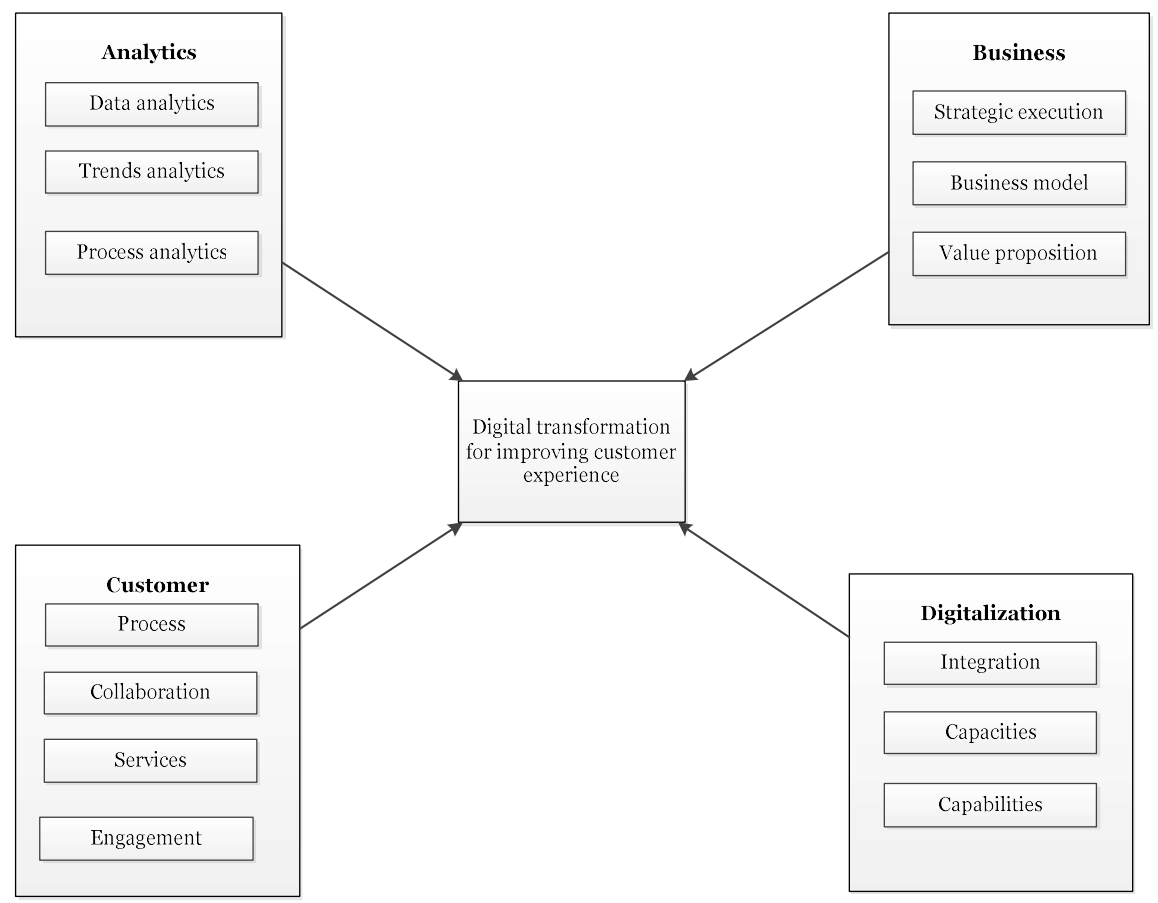

Figure 2: The digital transformation framework 
 \\ Digital transformation framework
}

\section{Conclusion}

This paper presents a capability-based framework for digital transformation towards improving customer experience in organisations. It unearthed several sub-dimensions within each dimension of the conceptual framework that can affect the outcome of digital transformation initiatives in organisations. The sub dimensions highlight various capabilities of digital transformation which enables organisations to improve customer experience, including data analytics, trends analytics, process analytics, strategic execution, business model, value proposition, process, collaboration, services, engagement, digital integration, digital capabilities, and digital capacities. Understanding the digital transformation framework would induce confidence to the leadership and senior management in organisations executing digital transformation.

This study contributes to the research of digital transformation from both the theoretical and the practical perspectives. From the theoretical perspective, this research contributes to the research related to digital transformation by developing a theoretical framework for implementing digital transformation for improving customer experience. From the practical perspective, this research would be helpful in organisations to facilitate implementing such initiatives effectively.

\section{REFERENCES}

Agarwal, R., Gao, G., DesRoches, C., and Jha, A. K. 2010. "Research Commentary-the Digital Transformation of Healthcare: Current Status and the Road Ahead," Information Systems Research (21:4), pp. 796-809.

Ajmal, M., Helo, P., and Kekäle, T. 2010. "Critical Factors for Knowledge Management in Project Business," Journal of knowledge management (14:1), pp. 156-168.

Alhojailan, M. I. 2012. "Thematic Analysis: A Critical Review of Its Process and Evaluation," West East Journal of Social Sciences (1:1), pp. 39-47.

Andal-Ancion, A., Cartwright, P. A., and Yip, G. S. 2012. "The Digital Transformation of Traditional Business," Image).

Ashurst, C., and Hodges, J. 2010. "Exploring Business Transformation: The Challenges of Developing a Benefits Realization Capability," Journal of Change Management (10:2), pp. 217-237.

Astri, L. Y. 2015. "A Study Literature of Critical Success Factors of Cloud Computing in Organizations," Procedia Computer Science (59), pp. 188-194.

Becker, J., Kugeler, M., and Rosemann, M. 2013. Process Management: A Guide for the Design of Business Processes. Springer Science \& Business Media.

Beetham, H., and Sharpe, R. 2013. Rethinking Pedagogy for a Digital Age: Designing for 21st Century Learning. Routledge.

Berman, S., and Marshall, A. 2014. "The Next Digital Transformation: From an Individual-Centered to an Everyone-to-Everyone Economy," Strategy \& Leadership (42:5), pp. 9-17.

Berman, S. J. 2012. "Digital Transformation: Opportunities to Create New Business Models," Strategy \& Leadership (40:2), pp. 16-24.

Bharadwaj, A., El Sawy, O. A., Pavlou, P. A., and Venkatraman, N. 2013. "Digital Business Strategy: Toward a Next Generation of Insights," Mis Quarterly (37:2), pp. 471-482.

Davenport, T. H. 2013. Process Innovation: Reengineering Work through Information Technology. Harvard Business Press.

Deng, H. and Gupta, P. (2005). Critical successful factors in information systems implementation: An end-user perspective. Proceedings of the 2005 Information Resources Management Association International Conference, May 15-18, San Diego, California, USA

Ding, X. D., Huang, Y., and Verma, R. 2011. "Customer Experience in Online Financial Services: A Study of Behavioral Intentions for Techno-Ready Market Segments," Journal of Service Management (22:3), pp. 344-366.

Duan, X., Deng, H., \& Corbitt, B. (2012). Evaluating the critical determinants for adopting e-market in Australian small-and-medium sized enterprises. Management Research Review, 35(3/4), 289-308. 
Fitzgerald, M., Kruschwitz, N., Bonnet, D., and Welch, M. 2014. "Embracing Digital Technology: A New Strategic Imperative," MIT Sloan management review (55:2), p. 1.

Greenberg, P. 2010. "The Impact of Crm 2.0 on Customer Insight," Journal of Business \& Industrial Marketing (25:6), pp. 410-419.

Hellbe, S., and Leung, P. 2015. "Digital Transformation: How Apis Drive Business Model Change and Innovation."

Henfridsson, O., Mathiassen, L., and Svahn, F. 2014. "Managing Technological Change in the Digital Age: The Role of Architectural Frames," Journal of Information Technology (29:1), pp. 27-43.

Hess, T., Matt, C., Benlian, A., and Wiesböck, F. 2016. "Options for Formulating a Digital Transformation Strategy," MIS Quarterly Executive (15:2).

Hilton, T., Hughes, T., Little, E., and Marandi, E. 2013. "Adopting Self-Service Technology to Do More with Less," Journal of Services Marketing (27:1), pp. 3-12.

Hsu, C.-C., and Sandford, B. A. 2007. "The Delphi Technique: Making Sense of Consensus," Practical assessment, research \& evaluation (12:10), pp. 1-8.

Kane, G. C., Palmer, D., Phillips, A. N., Kiron, D., and Buckley, N. 2015. "Strategy, Not Technology, Drives Digital Transformation," MIT Sloan Management Review and Deloitte University Press).

Karunasena. K., Deng, H., and Harasgama, K. S. (2013). An investigation of the critical factors for evaluating the public value of e-government: A thematic analysis. Information Systems and Technology for Organizations in a Networked Society. IGI Global, 213-233.

Kino, T. 2011. "Infrastructure Technology for Cloud Services," Fujitsu Sci. Tech. J (47:4), pp. 434-442.

Kiron, D., Shockley, R., Kruschwitz, N., Finch, G., and Haydock, M. 2012. "Analytics: The Widening Divide," MIT Sloan Management Review (53:2), p. 1.

Klaus, P., and Nguyen, B. 2013. "Exploring the Role of the Online Customer Experience in Firms' MultiChannel Strategy: An Empirical Analysis of the Retail Banking Services Sector," Journal of Strategic Marketing (21:5), pp. 429-442.

Lemon, K. N., and Verhoef, P. C. 2016. "Understanding Customer Experience Throughout the Customer Journey," Journal of Marketing (80:6), pp. 69-96.

Low, C., Chen, Y., and Wu, M. 2011. "Understanding the Determinants of Cloud Computing Adoption," Industrial management \& data systems (111:7), pp. 1006-1023.

Mathrani, S., and Viehland, D. 2010. "Critical Success Factors for the Transformation Process in Enterprise System Implementation," PACIS, p. 13.

Matt, C., Hess, T., and Benlian, A. 2015. "Digital Transformation Strategies," Business \& Information Systems Engineering (57:5), pp. 339-343.

Miles, M. B., and Huberman, A. M. 1994. Qualitative Data Analysis: An Expanded Sourcebook. sage.

Mithas, S., Tafti, A., and Mitchell, W. 2013. "How a Firm's Competitive Environment and Digital Strategic Posture Influence Digital Business Strategy," Mis Quarterly (37:2), pp. 511-536.

Nwankpa, J. K., and Roumani, Y. 2016. "It Capability and Digital Transformation: A Firm Performance Perspective,").

Nylén, D., and Holmström, J. 2015. "Digital Innovation Strategy: A Framework for Diagnosing and Improving Digital Product and Service Innovation," Business Horizons (58:1), pp. 57-67.

Olszak, C. M., and Ziemba, E. 2012. "Critical Success Factors for Implementing Business Intelligence Systems in Small and Medium Enterprises on the Example of Upper Silesia, Poland," Interdisciplinary Journal of Information, Knowledge, and Management (7:12), pp. 129-150.

Piccinini, E., Gregory, R. W., and Kolbe, L. M. 2015. "Changes in the Producer-Consumer RelationshipTowards Digital Transformation," Wirtschaftsinformatik, pp. 1634-1648.

Rajabi, M., and Bolhari, A. 2015. "Business Transformations: Inevitable Changes of the Era," Optimization of Supply Chain Management in Contemporary Organizations), p. 61.

Ravesteyn, P., and Batenburg, R. 2010. "Surveying the Critical Success Factors of Bpm-Systems Implementation," Business Process Management Journal (16:3), pp. 492-507. 
Ryan, D. 2016. Understanding Digital Marketing: Marketing Strategies for Engaging the Digital Generation. Kogan Page Publishers.

Sahney, S. 2015. "Critical Success Factors in Online Retail-an Application of Quality Function Deployment and Interpretive Structural Modeling," International Journal of Business and Information (3:1).

Sahu, N.,Deng, H., and Molla, A. 2018. "Investigating the critical success factors of digital transformation for improving customer experience," International Conference on Information Resources Management 2018.

Sambamurthy, V., and Zmud, R. W. 2012. Guiding the Digital Transformation of Organizations. Legerity Digital Press.

Spiess, J., T'Joens, Y., Dragnea, R., Spencer, P., and Philippart, L. 2014. "Using Big Data to Improve Customer Experience and Business Performance," Bell Labs Technical Journal (18:4), pp. 3-17.

Straker, K., Wrigley, C., and Rosemann, M. 2015. "Typologies and Touchpoints: Designing MultiChannel Digital Strategies," Journal of Research in Interactive Marketing (9:2), pp. 110-128.

Tassey, G. 2012. Technology Infrastructure and Competitive Position. Springer Science \& Business Media.

Teece, D. J., Pisano, G., and Shuen, A. 1997. "Dynamic Capabilities and Strategic Management," Strategic management journal), pp. 509-533.

Thirumalai, S., and Sinha, K. K. 2011. "Customization of the Online Purchase Process in Electronic Retailing and Customer Satisfaction: An Online Field Study," Journal of Operations Management (29:5), pp. 477-487.

Ward, J., and Peppard, J. 2016. The Strategic Management of Information Systems: Building a Digital Strategy. John Wiley \& Sons.

Westerman, G., and Bonnet, D. 2015. "Revamping Your Business through Digital Transformation," MIT Sloan Management Review (56:3), p. 10.

Westerman, G., Bonnet, D., and McAfee, A. 2014a. Leading Digital: Turning Technology into Business Transformation. Harvard Business Press.

Westerman, G., Bonnet, D., and McAfee, A. 2014b. "The Nine Elements of Digital Transformation," MIT Sloan Management Review (7).

Westerman, G., Calméjane, C., Bonnet, D., Ferraris, P., and McAfee, A. 2011. "Digital Transformation: A Roadmap for Billion-Dollar Organizations," MIT Center for Digital Business and Capgemini Consulting).

Copyright: (C) 2018 authors. This is an open-access article distributed under the terms of the Creative Commons Attribution-NonCommercial 3.0 Australia License, which permits non-commercial use, distribution, and reproduction in any medium, provided the original author and ACIS are credited. 